\title{
Municipal Solid Waste Management in Nepal: Opportunities and Challenges
}

\author{
Mohan Krishna Maharjan ${ }^{1,}$, Sunil Prasad Lohani ${ }^{1}$ \\ ${ }^{I}$ Department of Mechanical Engineering, School of Engineering, Kathmandu University \\ Corresponding email: maeronauticslgmail.com
}

\begin{abstract}
:
Solid waste management at municipalities of Nepal is one of the major issues that require a sustainable solution. The preliminary survey and review suggested that waste management practices including collection, transport and resource recovery in most of the municipalities are ineffective and almost all collected waste finally disposed to the dumping site. Taking baseline data from solid waste management in Nepal report of Asian Development Bank 2013, estimated waste projection of 2017 has been made. The projected data shows waste generation in municipalities of Nepal is about 3023 tons per day and the average per capita waste generation is $0.223 \mathrm{~kg} /$ person/day. On average the composition of waste is primarily decomposable about $60 \%$ and about $25 \%$ is recyclables such as plastics, papers and metals. With the help of Multi Criteria Decision Matrix (MCDM), this paper suggests that the suitable methods of waste management for Nepalese municipalities are waste to bio-energy and fertilizer production. It further proposed and discussed a holistic model of waste management for municipalities and an appropriate waste to bio-energy technology in context of Nepal.
\end{abstract}

Keywords: Solid Waste Management, Bioenergy, Waste Volume and Composition, Organic Waste

\section{Introduction}

The development and facilities are built for making people's life easy. People are using more resources than in past thus simultaneously generating more waste.

In context of Nepal, many municipalities effort to manage solid waste are inadequate, and it in turn generates many other problems related to environment and ultimately human health.

The reliable estimates of MSW generation are vital for effective waste management planning and help taking better financial, regulatory and institutional decisions. In addition, the solid waste should be characterized for source, generation rates, type of wastes produced and their composition.

The present status of waste management in almost all municipalities is open dumping and landfilling without any treatment. It decreases the life of landfill site. The municipalities need short- and long-term planning to manage waste in actual sense.

There are 270 municipalities in Nepal including 4 metropolitan, 10 sub-metropolitan and 256 municipalities [1].

Taking baseline data from solid waste management in Nepal report of Asian Development Bank 2013, the estimated waste projection of 2017 has been made. The projected data shows waste generation in municipalities of Nepal is about 3023 tons per day and the average per capita waste generation is $0.223 \mathrm{~kg} /$ person/day. On average the composition of waste is primarily decomposable about $60 \%$ and about $25 \%$ is recyclables such as plastics, papers and metals [2,3].

The waste management approaches in most municipalities in Nepal are similar. The three major processes involved in waste management are collection, transport and landfill disposal of waste [4].

The municipalities face problems such as lack of technical support, financial constraints, waiting for the government's decision and approval for land acquisition of proposed landfill sites, problems in area selection, and strong opposition from nearby communities. Other geographical problems like flooding, shallow water table, highly permeable soil, and slope instability also exist in the selected area. The characteristics of the generated waste depends on physical factors, such as altitude, temperature, rainfall, and humidity, as well as socioeconomic factors, such as population, economic status, and consumption patterns [2].

Depending upon the location of municipalities, the application of waste treatment technology and final 
disposing method varies. So, the geographic location of municipalities provides us idea about managing waste.

This paper aims at presenting an appropriate waste to energy technology and waste management method for the municipalities in Nepal through Multi Criteria Decision Matrix (MCDM).

The paper has also proposed a holistic model for Solid Waste Management.

\section{Approach and Methodology}

The study tries to compare two different waste management technologies namely anaerobic digestion and incineration. The criteria have been selected and used in building MCDM for comparing these technologies, and then identifying the most appropriate waste management model and waste to energy technology. The paper has developed the criteria for the selection of the technology based on the waste characterization, waste generation, economic aspects, etc. which could make the specific technology to be more viable and implementable in the municipalities of Nepal.

\subsection{MCDM for Selection of Waste to Energy Technology}

The Multi Criteria Decision Matrix has been used to identify the appropriate waste to energy technology in view of waste characteristics of Nepal. The criteria developed for MCDM has been defined with their importance for the selection of the most appropriate waste to energy technology for Nepal.

\subsubsection{Define the Criteria for Selection}

The criteria for the selection of the technology have been clearly defined in order to outline the clarity of most appropriate technology in context of Nepal. The multicriteria decision matrix used in this study is based on the following criteria: 1. GHG Emission, 2. Economic aspect, 3. Volume Reduction of Waste, 4. Moisture Content, 5. Waste Composition

\subsubsection{GHG Emission}

Greenhouse gas absorbs and emits radiant energy within the thermal infrared range. Increasing greenhouse gas emissions cause the greenhouse effect. The primary greenhouse gases in earth's atmosphere are water vapor, carbon dioxide, methane, nitrous oxide and ozone, which are the major gases that get generated through waste. So, the technology selected for the waste management system would take the account of its potentiality to calculate possible amount of reduced GHG emission.

\subsubsection{Economic Aspect}

It is one of the important aspects during the selection of waste to energy technology because it defines which technology is economically viable to fit the local context.

\subsubsection{Volume Reduction of Waste}

The maximum use of waste i.e. wastes for energy, fertilizer, etc. depends upon the method and technology to treat waste which in turn reduces the waste quantity. Furthermore, it accounts for less amount of waste finally disposed to the landfill which ultimately increases the life of the landfill.

\subsubsection{Moisture Content}

It is an important factor while selecting the right waste to energy technology especially for waste generated by municipalities in Nepal. These wastes are enriched with water content.

\subsubsection{Waste Composition}

Another important factor is the waste characteristics of municipal solid waste in Nepal. It plays a vital role during the selection of the appropriate technology i.e. justifying either organic waste or inorganic waste being more in composition, and which technology suits for particular composition of the waste.

\subsubsection{Identification of appropriate waste to energy technology}

As discussed above, the technologies used for the comparison are anaerobic digestion and incineration. The criteria described above were given specific weightage. The weight index has been built with specific weightage from 1 to 3 which has been illustrated in Table 1 [5]. The most important criteria are defined with weightage 3 and least important for the consideration is given weightage 1. The respective other values of weightage are defined for the importance of one aspect over other. The percentage of decision for the specific criteria shown in Table 1 plays a vital role in the selection of the appropriate technology. In Table 2, these criteria were given specific points range from 1 to 10 with respect to the technology selected $[5,6]$. The raw score for each technology was calculated directly by the summation of specific point (1 to 10) given to the specified criteria. The weightage (1 to 3 ) given to the specified criteria as illustrated in Table 1 was multiplied with the specific point (1 to 10 ) provided to the specified 
criteria with respect to the technology as shown in Table 2. The weighted score for each technology was calculated by the addition of these multiplied values. The technology with highest weighted score was ranked 1st, and the same technology was selected as the proposed one [6].

Table 1: Weightage and Percentage of Decision for Criteria

\begin{tabular}{|l|l|l|l|}
\hline Weight & Criteria & Rank & \% of Decision \\
\hline 1 & GHG Emission & 5 & 10 \\
\hline 2 & Economic Aspect & 4 & 19 \\
\hline 2.0 & Volume Reduction of & 3 & 19 \\
\hline 2.5 & Moisture Composition & 2 & 24 \\
\hline 3 & Waste Composition & 1 & 29 \\
\hline
\end{tabular}

\section{Opportunities and Challenges}

Based on the available municipal waste data, and the waste management system not being properly managed in the municipalities of Nepal, it can be easily be inferred that an opportunity for managing the waste via resource recovery through recycling, composting, and in the form of energy is enormous [7].

However, there are few challenges that we need to face during the implementation such as financial constraints and technical constraints. The collection should be efficient with proper method of segregation, which would be difficult at local and municipal level initially. The method of segregation should be maintained in transport vehicles to the transfer station, by where waste can be decided to be taken to either power plant, recycle plant or landfill. The management of waste would face obstacles during the implementation.

\section{$4 \quad$ Results and Discussion}

\subsection{Results of MCDM}

The use of multi criteria decision matrix for the selection of waste to energy technology has ranked anaerobic digestion as the most appropriate technology in context of Nepal. The use of this technology is totally based on MCDM.

\subsection{Waste Management Model}

The concept of waste management starts with the generation of waste and understanding of its composition. The study also focuses on several communities in world with better SWM practices, which has given us the clear understanding of various approaches for better waste management to be implemented in the municipalities of Nepal [8-12].

Table 2: MCDM, Summary of Decision

\begin{tabular}{|c|c|c|c|}
\hline \multirow{2}{*}{\multicolumn{2}{|c|}{ Criteria (Weight) }} & \multicolumn{2}{|c|}{ Options } \\
\hline & & $\begin{array}{l}\text { Anaerobic } \\
\text { Digestion }\end{array}$ & Incineration \\
\hline \multicolumn{2}{|c|}{ GHG Emission (1) } & 9 & 2 \\
\hline \multicolumn{2}{|c|}{ Economic Aspect (2) } & 8.9 & 6.3 \\
\hline \multicolumn{2}{|c|}{ Volume Reduction of Waste (2) } & 5.5 & 9.2 \\
\hline \multicolumn{2}{|c|}{ Moisture Composition (2.5) } & 7 & 5 \\
\hline \multicolumn{2}{|c|}{ Waste Composition (3) } & 6.5 & 4 \\
\hline \multirow{3}{*}{ Result } & Raw Score & 36.9 & 26.5 \\
\hline & Weighted Score & 74.8 & 57.5 \\
\hline & Rank & 1 & 2 \\
\hline
\end{tabular}

Thus, this paper has also proposed a holistic waste management model for the municipalities in Nepal which has been illustrated in Figure 1. The paper has also identified two major factors: 1 . Strong act and regulation regarding waste management, and its proper supervision by the concerned authority and 2 . The involvement and participation of community in waste management program through awareness. These are the important aspects to be addressed before implementing the better waste management program.

The holistic waste management model begins with the proper segregation and collection of waste from different sources such as from households, hotels, restaurants, etc. The separate bins should be kept by households and institutions to separately store bio-degradable, nondegradable waste like plastics and electronic waste.

The collected waste with proper segregation needs to be transported to the specific areas by trucks, tractors, rickshaws, etc. depending upon the situations. In local areas with small road, rickshaw is the best option. For large coverage, mini-trucks can be used unless the roads are big. There should be special provision for collecting the waste in separate container itself in the vehicle and the person going for collection should properly ask and ensure himself by interacting with community people about the type of waste they collect.

The collected waste should be transported to an appropriate disposal facility, called transfer station. It is the temporary deposition site for processing waste. If possible, we could make the transfer station as material recovery facilities and localized mechanical biological 


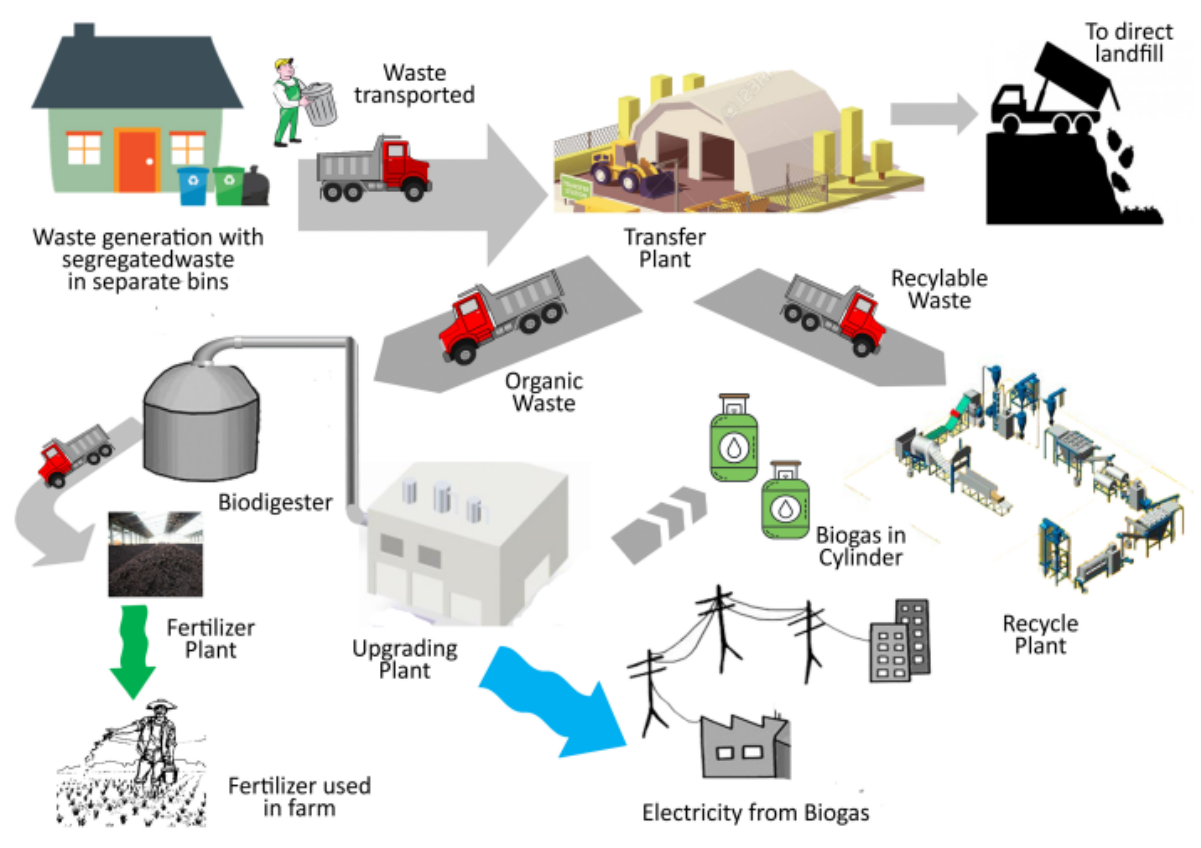

Figure 1: Waste Management Model

treatment systems to remove recyclable items from the material recovery facilities.

After proper segregation of the waste, we need to decide what to do with the segregated waste. There are various methods to process and treat the waste. The waste, depending on the nature, can be reused, recycled, use for energy recovery, use resource recovery, etc.

Here, waste is extracted as a recovery material or waste to be converted to energy. It has benefits of decreasing amount of waste finally moving to landfill so saving space and increasing life of it. Recycling is another resource recovery practice. It refers to the recycling of waste materials such as pet bottles, plastics, etc.

By the study of waste volume, composition and scenarios in the municipalities in Nepal, it would be beneficial and appropriate if we can implant anaerobic digestion plant to convert waste to energy which has been already discussed.

The great advantages lie in this process are the large volume of substrate, which can be used as fertilizers in agricultural fields as Nepal being an agricultural country.

The waste that is to be deposited finally in landfill should be the real waste in terms of, the waste that has no other option for further processing and treatment. It could be the glass waste, sterilized medical waste (not the scope of the study), broken mirrors, dust, dirt, ceramics, etc. The various methods of landfilling can be adopted to increase the life of the landfill and to make it sanitary.

\section{Conclusion}

In this study, the appropriate waste to energy technology has been identified with the help of MCDM. The results have shown that the anaerobic digestion is the most suitable technology for the municipalities in Nepal. Furthermore, the paper has also proposed and designed a holistic waste management model which could be used for the better management of waste within the municipalities in Nepal. The paper provides a better clarity of waste management by firstly collecting and segregating waste at household and local level, secondly recycling and reclaiming materials or recovering waste in form of energy at recycle or energy plant, and finally if nothing can be done with the waste then disposing it into the landfill with proper landfilling techniques.

The important aspects that directly affects the waste management has also been identified. There needs a strong regulation regarding waste management and community itself should be made equally responsible for the management of the waste through awareness program in the community. The authority itself should be strong enough to manage the waste. The moral aspect and attitude towards waste should be changed specially from the authority and institutional level so that others could learn from them.

\section{Acknowledgments}

The authors are thankful to the Department of Mechanical Engineering, Kathmandu University for giving the 
platform to initiate the study. The authors would also like to acknowledge the Solid Waste Management Research Mobilization Centre (SWMRMC) for providing data, and Alternate Energy Promotion Centre (AEPC) for sharing their valuable experience on technology for waste to energy.

\section{References}

[1] Rapnepal (March 2017), Retrieved from http://rapnepal.com/sites/default/files/reportpublication/local govt of 75 districts23mar2017.pdf.

[2] Asian Development Bank (2013), "Solid Waste Management in Nepal Current Status and Policy Recommendations".

[3] Pathak, D. R. (January 2017), "Solid Waste Management Baseline Study of 60 New Municipalities", Tribhuvan University, Nepal, Tech. Report. 10.13140/RG.2.2.11930.24006/1.

[4] Singh, R. K., Yabar, H., \& Mizunoya, T. (2014), "Potential Benefits of Introducing Integrated Solid Waste Management Approach in Developing Countries: A Case Study in Kathmandu City", University of Tsukuba, Japan.

[5] Martowibowo, S. Y., \& Riyanto, H. (2011), "Suitable Multi Criteria Decision Analysis Tool for Selecting Municipal Solid Waste Treatment in The City of Bandung", Institut Teknologi Bandung, Faculty of Mechanical and Aerospace Engineering.

[6] Lin, Y. P., \& Ching-Yuan Chang, C. Y. (October 2015), "A Multi-Criteria Decision Analysis of Waste Treatment Options for Food and Biodegradable Waste Management in Japan", Graduate School of Asia Pacific Studies, Ritsumeikan Asia Pacific University.

[7] Pokhrel, D. \& Viraraghavan, T. (March 2005), "Municipal solid waste management in Nepal: practices and challenges", University of Rejgina, Canada.

[8] P. S., \& PVS, J. (2012), "Solid waste management in Chennai city", Bharathi Women's College, Chennai, India.

[9] Mahajan, N. (2016), "Solid Waste Management in Chennai: Lessons from Exnora”, Waseda University, Tokyo, Japan.

[10] Riyad, A.S.M., Farid \& Hossain, S. K. (2014), "Challenges of Waste Generation \& Improvement of Existing Scenario in Commercial City of Bangladesh", Khulna University of Engineering \& Technology, Bangladesh.

[11] Ministry of Community Development (2009), "Resources from Waste: A Guide to Integrated Resource Recovery", British Columbia.
[12] Ashan, A., Alamgir, M., El-Sergany, M.M., Shams, S., Rowshon, M. K. \& Nik Daud, N. N. (2014), “Assessment of Municipal Solid Waste Management System in a Developing Country'. 